\title{
BMJ Open Geographical variation in musculoskeletal surgical care in public hospitals in Ireland: a repeated cross- sectional study
}

\author{
Mary E Walsh, ${ }^{\oplus}$ Fiona Boland, ${ }^{\oplus 1}$ John M O'Byrne, ${ }^{2}$ Tom Fahey ${ }^{1}$
}

To cite: Walsh ME, Boland F, O'Byrne JM, et al. Geographical variation in musculoskeletal surgical care in public hospitals in Ireland: a repeated crosssectional study. BMJ Open 2019;9:e028037. doi:10.1136/ bmjopen-2018-028037

- Prepublication history and additional material for this paper are available online. To view these files, please visit the journal online (http://dx.doi. org/10.1136/bmjopen-2018028037).

Received 19 November 2018 Revised 9 April 2019 Accepted 17 April 2019

Check for updates

(c) Author(s) (or their employer(s)) 2019. Re-use permitted under CC BY-NC. No commercial re-use. See rights and permissions. Published by BMJ.

${ }^{1}$ HRB Centre for Primary Care Research, Department of General Practice, Royal College of Surgeons in Ireland, Dublin, Ireland

${ }^{2}$ Professorial Unit, RCSI at Cappagh National Orthopaedic Hospital, Royal College of Surgeons in Ireland, Dublin, Ireland

Correspondence to Dr Mary E Walsh;

maryewalsh@rcsi.ie

\section{ABSTRACT}

Objective To examine the extent of geographical variation across musculoskeletal surgical procedures and associated factors in Ireland.

Design Repeated cross-sectional study.

Setting 36 public hospitals in Ireland.

Participants Adult admissions for hip fracture, hip and knee replacement, knee arthroscopy and lumbar spine interventions over 5 years (2012-2016).

Primary outcome measure Standardised discharge rate (SDR).

Analysis Age and sex SDRs were calculated for 21 geographical areas. Extremal quotients, coefficients of variation and systematic components of variance were calculated. Linear regression analyses were conducted exploring the relationship between SDRs and year, unemployment, \% urban population, number of referral hospitals, $\%$ on waiting lists $>6$ months and $\%$ with private health insurance for each procedure.

Results Across 36 public hospitals, $n=102756$ admissions were included. Hip fracture repair showed very low variation. Elective hip and knee procedures showed high variation in particular years, while variation for lumbar interventions was very high. Knee arthroscopy rates decreased over time. Higher unemployment was associated with knee and hip replacement rates and urban areas had lower hip replacement rates. Spinal procedure rates were associated with a lower number of referral hospitals in a region and spinal injection rates were associated with shorter waiting lists. A higher proportion of patients having private health insurance was associated with higher rates of hip and knee replacement and lumbar spinal procedures.

Conclusions Variation and factors associated with SDRs for publicly funded hip and knee procedures are consistent with similar international research in this field. Further research should explore reasons for high rates of spinal injections and the impact of private practice on musculoskeletal procedure variation.

\section{INTRODUCTION}

Variations in healthcare procedures and practice can sometimes be appropriate reflecting the differences in healthcare needs across different populations. ${ }^{1}$ However, significant unwarranted variation in healthcare
Strengths and limitations of this study

- This study uses a large national dataset which is known to have good coverage and accuracy across public hospitals.

- Methods of quantifying variation are in line with international work.

- We could not include procedures conducted within private hospitals.

- An analysis of factors associated with the variation was explored, however, results should be considered exploratory due to data availability.

- Differences in the definitions and denominators used in national atlases of healthcare variation in different countries limit the ability to make direct international comparisons of standardised discharge rates.

does exist. ${ }^{1}$ In evaluations of clinical practice variation, care has been grouped into three domains with different implications for patients, clinicians and policy makers ${ }^{2}$ :

- 'Effective care' is defined as interventions for which the benefits far outweigh the risks and unwarranted variation is generally a matter of underuse.

- 'Preference sensitive care' occurs when more than one generally accepted treatment option is available. In this case, the rate depends on patient and professional decision making.

- 'Supply-sensitive care' comprises clinical activities for which the frequency of use relates to the capacity of the local healthcare system.

In relation to musculoskeletal care, practice variation has been widely studied for surgical procedures used to treat pain caused by degenerative musculoskeletal conditions including spinal surgery for back pain and joint replacements for arthritis of the knee and hip. ${ }^{3}$ Several international guidelines recommend reserving surgical intervention for cases with clear indication or that have 
not responded to conservative management including pharmacological treatments and physiotherapy. ${ }^{45}$ The level of geographic variation observed internationally to date has varied by country and procedure. For hip and knee replacements, twofold variation has been observed in Europe and fivefold in the USA. ${ }^{6-11}$ For spinal fusion, approximately fivefold variation has been observed in Europe and up to 20 -fold in the USA. ${ }^{11}{ }^{12}$ In the USA, studies of musculoskeletal procedures have focused on the domain of 'preference-sensitive care'. ${ }^{11}$ In contrast, in countries with predominantly publicly funded hospital services including Ireland, the UK and Canada, considerable waiting lists for orthopaedic procedures may influence provision and cause 'supply-sensitive' variation. ${ }^{2}$

In Ireland, minimal research has been conducted into the causes of potentially unwarranted variation of musculoskeletal procedures, although analyses conducted by the Health Information and Quality Authority (HIQA) ${ }^{513}$ suggest that significant variation for several elective musculoskeletal procedures does exist within the public system. HIQA also highlighted the need for increased clarity around clinical referral thresholds for these procedures to help increase equity of care and minimise treatment overuse. $^{513}$

The first step to address unwarranted variation in healthcare is the systematic, routine collation and publication of data on such variations. ${ }^{14}$ Detailed multivariable analysis of factors associated with musculoskeletal surgical variation in Ireland is required in order to establish if variation is unwarranted and if it is leading to inequitable access to publicly funded care. The aim of this study is to examine the extent of geographical variation in musculoskeletal procedures in public hospitals in Ireland, with a focus on the most common and costly procedures. Our secondary aim was to explore potential causes for any variation identified.

\section{METHODS}

The Strengthening the Reporting of Observational Studies in Epidemiology guidelines were used to guide the conduct and reporting of this study. ${ }^{15}$

\section{Setting}

As of 2016, Ireland has a population of 4.7 million people. Ireland's healthcare system is characterised by a complex mixture of public and private delivery and financing with different routes of access. ${ }^{16}$ All persons resident in the state are entitled to receive hospital care through the publicly funded healthcare system. There are however considerable delays within this system. As of September 2018, there were 9600 patients listed as waiting for an orthopaedic procedure in public hospitals in the country with $37 \%$ of these individuals waiting for over 6 months. ${ }^{17}$ This is in addition to the time spent waiting for diagnostic tests and appointments with hospital consultants. As of 2017 , approximately $43 \%$ of the population held private health insurance which may entitle them to avoid long delays and access elective orthopaedic and pain management in up to 17 private hospitals in the country. ${ }^{18}$ Hospital consultants may hold contracts that permit them to conduct private practice within public hospitals, for which they earn private fees on top of their salaries. Public and private patients receiving treatment in public hospitals however are assigned priority for procedures on a common waiting list. ${ }^{16} 19$ The current study explores variation across public hospitals but not private hospitals in Ireland.

\section{Participant selection}

An anonymous dataset of admissions with a discharge date between 2012 and 2016 inclusive, with a minimum patient age of 18 years were extracted from the national Hospital Inpatient Enquiry (HIPE) system. HIPE is the principal source of information on all inpatient and day case discharges from and deaths in publicly funded acute hospitals in Ireland with over 99\% coverage each year. ${ }^{20}$ Further information about this dataset is available in the online supplementary table 1 . For this analysis, admissions were excluded for those not resident in Ireland. All hospital admissions, including those defined as 'inpatient', 'day case', 'emergency' and 'elective', were selected. ${ }^{20}$ While data from private hospitals were not included in this study, patients who had private health insurance but were treated within a public hospital were included.

Admissions with the following procedures were selected: hip replacement, knee replacement, knee arthroscopy, spinal procedures for lumbar degenerative disease, spinal injections for lumbar degenerative disease and surgical hip fracture repair (see online supplementary table 2, which shows detailed definitions of selected admissions with International Statistical Classification of Diseases and Related Health Problems, Tenth Revision, Australian Modification [ICD-10-AM ] codes). ${ }^{21}$

These groups of admissions were chosen to allow comparisons with the majority of international research in the field and previous national analyses of practice variation. ${ }^{3510132223}$ Hip fracture admissions were selected for investigation as surgical repair for this diagnosis is widely defined as 'effective care' and low levels of unwarranted variation would be expected. ${ }^{11}$ This has been used in other similar research as a comparative measure. ${ }^{10} 1224$

Formal ethical approval was not sought for this study as it was conducted using existing national anonymous administrative and publicly available datasets.

\section{Definition of small areas and calculation of standardised discharge rates (SDRs)}

Within the HIPE system, area of residence is coded at the county level with the exception of the largest county (Dublin) which is further delineated by postcode. ${ }^{20}$ Age-stratified and sex-stratified population counts for persons over the age of 18 in each of the 26 counties in Ireland and the areas of North Dublin and South Dublin, were obtained based on the 2011 and 2016 national 
censuses. ${ }^{25}$ Further information about census methodology can be found in the online supplementary table 1 . The population estimates for the intercensus years were calculated by assuming a uniform annual growth rate. Based on referral patterns for elective musculoskeletal procedures, small counties were grouped with neighbouring counties in order to produce more stable estimates of variation. ${ }^{26}$ The county of Dublin was split into North and South Dublin due its relatively large population (29\% of the national adult population in 2016). Thus, a total of 21 small areas were defined. For each of the six selected procedures, discharge rates per 100000 adult residents were calculated by year and small area. Rates were indirectly standardised for sex and age using the 2013 WHO European Standard Population. ${ }^{27}$

\section{Quantifying variation}

The extent of variation in SDRs for each procedure across small areas was estimated using the extremal quotient (EQ, maximum rate divided by minimum rate), the coefficient of variation $(\mathrm{CV}$, ratio of $\mathrm{SD}$ of rates to mean of rates) and the systematic component of variance (SCV).$^{28}{ }^{29}$ Each variable was also calculated eliminating outliers beyond the 5-95 percentiles $\left(\mathrm{EQ}_{5-95}, \mathrm{CV}_{5-95}, \mathrm{SCV}_{5-}\right.$ $\left.{ }_{95}\right){ }^{12} 2829$ The SCV, a robust measure that represents the true, non-random part of observed variations, is calculated by

$$
\frac{1}{k}\left(\sum_{i=1}^{k} \frac{\left(O_{i}-E_{i}\right)^{2}}{E_{i}^{2}}-\sum_{i=1}^{k} \frac{1}{E_{i}}\right)
$$

where $k=21$ (the number of small areas), $O_{i}$ is the observed number of discharges in the $i$ th small area and $E_{i}$ is the expected number determined by indirect standardisation. ${ }^{129}$ An SCV value of $>3$ is likely to be due largely to practice style differences, $>5$ is indicative of high variation and $>10$ is considered very high variation. ${ }^{129}$

\section{Explaining variation}

Geographic variation can be associated with healthcare supply-and-demand-related factors. ${ }^{24}$ Variables at the small-area level were derived from several data sources to explore these factors. Unemployment rate was calculated from census data as a proxy for the socioeconomic status of an area, which has been found to influence demand for healthcare. ${ }^{30}$ The proportion of the population living in urban areas (in towns with populations of 1500 or more) were also calculated from the census ${ }^{25}$ as this could affect both the availability of services and the ability to manage a chronic pain condition. ${ }^{31}$

Limited data were available at the small-area level in relation to the supply of relevant healthcare services. The proportion of patients using private insurance for each procedure was calculated and explored as a proxy for the availability of private hospital care in an area. Data on the numbers waiting for inpatient and day case procedures broken down by hospital name and clinical specialty are published by the National Treatment Purchase Fund. ${ }^{17}$
We constructed an exploratory variable for the purposes of this analysis whereby each small area was assigned a number of 'referral hospitals' for each group of procedures under study and each group of procedures was assigned to a number of clinical specialties. This allowed us to create an estimate of the proportion of individuals waiting more than 6 months for a procedure on relevant lists. Further details on the derivation of this variable, as well as the accuracy and coverage of waiting list data, is available in online supplementary table 1 . The number of hospitals offering a service in each area could also be a source of variation. We therefore considered the number of 'referral hospitals' as a separate exploratory variable.

Linear regression analysis was conducted for each procedure with standardised discharge rate as the outcome. Area-level explanatory variables included year, unemployment rate, proportion of the population living in an urban area, number of referral hospitals, the proportion on relevant waiting lists for more than 6 months and the proportion of patients with each procedure who were covered by private health insurance. A random effect to account for clustering within small area was also included in the models. Stata V.14 (StataCorp) was used for all statistical analyses.

\section{Patient and public involvement}

Patients were not involved in the conception, design or conduct of this research.

\section{RESULTS \\ Demographics}

The mean number of adults in the population per small area in 2011 was 163789 (range 73599-541231) and in 2016 was 170065 (range 73430-567424). The following analysis includes records from $\mathrm{n}=102756$ admissions over 5 years from 36 public hospitals. Demographics and clinical characteristics are presented in table 1 by procedure. While lumbar spinal injections make up the largest category of procedure, they had the shortest length of stay and at least a quarter were repeat admissions. Those with joint replacements and hip fracture repair were older on average than those with knee arthroscopies and interventions for lumbar spine disease.

\section{SDRs}

Figure 1 shows dotplots of SDRs for different procedures across 5 years. It is evident that the SDR for knee arthroscopies has decreased over the study period.

\section{Quantifying variation}

Table 2 shows the level of variation across procedures. As expected, the rate of hip fracture repair shows very low geographic variation $(\mathrm{SCV}<1)$. Knee replacement shows high variation in particular years (twofold, SCV $>5$ ) and hip replacement shows high variation in all years studied (2.5-fold to 3-fold, SCV >5). Geographic variation for knee arthroscopies and lumbar spine procedures is very high in 


\begin{tabular}{|c|c|c|c|c|c|c|c|c|}
\hline Procedure & $\begin{array}{l}\text { Total no. of } \\
\text { admissions }\end{array}$ & $\begin{array}{l}\text { Mean age } \\
\text { (SD) }\end{array}$ & Male \% & $\begin{array}{l}\text { 'Private' } \\
\text { patient \%* }\end{array}$ & $\begin{array}{l}\text { Elective } \\
\text { admission \% }\end{array}$ & $\begin{array}{l}\text { Mean LOS in } \\
\text { days (SD) }\end{array}$ & $\begin{array}{l}\text { Day case } \\
\text { procedure \% }\end{array}$ & $\begin{array}{l}\text { Repeat } \\
\text { patient \%† }\end{array}$ \\
\hline Knee replacement & 12151 & $67.1(9.9)$ & 41.2 & 27.7 & 98.3 & $6.3(8.0)$ & 0.3 & 5.6 \\
\hline Knee arthroscopy & 15089 & $46.2(15.5)$ & 62.0 & 36.1 & 95.7 & $1.6(5.7)$ & 78.1 & 3.4 \\
\hline $\begin{array}{l}\text { Lumbar spinal } \\
\text { injection }\end{array}$ & 33880 & $56.0(15.9)$ & 39.1 & 32.0 & 98.5 & $1.1(1.9)$ & 97.8 & 25.7 \\
\hline Hip fracture repair§ & 16101 & $79.2(10.2)$ & 29.4 & 24.6 & 0.6 & $19.1(26.0)$ & 0.1 & 2.0 \\
\hline
\end{tabular}

${ }^{*}$ Refers to those covered by private health insurance during stay in public hospital.

†Due to data available it is not possible to identify individual patients if they attend different hospitals. Proportion shown is therefore a minimum estimation of repeat patients.

‡Excluding principle diagnosis of hip fracture.

§Principle diagnosis, over age of 50, excluding those transferred to other hospital within 2 days of admission.

LOS, length of stay.

several years (threefold to fivefold, SCV $>10$ ). Variation is particularly high for lumbar injections (12-fold to 14-fold, SCV >40) and remains high when areas with rates in the fifth and 95th percentile are excluded (see online supplementary table 3 , which shows national crude and standardised rates, EQ5-95, $\mathrm{CV}_{5-95}$ and $\left.\mathrm{SCV}_{5-95}\right)$.

\section{Explaining variation}

Table 3 shows a description of small-area level variables used to explore variation (see online supplementary table 4 , which lists the 21 small areas and demographic variables for census years). Knee replacement rate was significantly lower in 2014 than 2012 (unadjusted coefficient: -11.0 (95\% CI -18.1 to -3.9$)$ ). Knee arthroscopy rates were lower each year when compared with 2012 (unadjusted coefficients for 2014: -10.2 (95\% CI -16.8 to -3.7$)$, for 2015: -15.4 (95\% CI -25.2 to -5.5 ) and for 2016 : $-20.8(95 \%$ CI -30 to -11.5$))$. With adjustment for other factors, areas with a lower proportion of the population living in urban areas had higher rates of hip replacement (adjusted coefficient ( -102.7 (95\% CI -138.5 to -66.9$))$ ). Areas with higher unemployment rates had higher hip replacement rates (adjusted coefficient 384.7 (95\% CI 70 to 699.5$)$ ) and higher knee replacement rates (adjusted coefficient 596.8 (95\% CI 331.4 to 862.3)). Lumbar spinal procedure rate was associated with fewer referral hospitals (adjusted coefficient -3.1 (95\% CI -5.5 to -0.8$)$ ). Higher spinal injections rates were associated with lower proportions of people on relevant waiting lists for $>6$ months (adjusted coefficient -557 (95\% CI -1018.4 to -95.5$)$ ). A higher proportion of patients having private health insurance for each procedure was associated with higher rates of hip replacement (adjusted coefficient (153.2 (95\% CI 80.6 to 225.9))), knee replacement (adjusted coefficient (87.2 (95\% CI 48.6 to 125.7))) and lumbar spinal procedures (adjusted coefficient (35.8 (95\% CI 20.2 to 51.5))) (see online supplementary table 5, which shows the full univariable and multivariable results of linear regression analysis with SDRs as the outcome).

\section{DISCUSSION \\ Summary of principle findings}

This study explored geographical variation across six of the most common and costly musculoskeletal surgical procedures conducted in public hospitals in Ireland between the years 2012 and 2016. In comparison to variation in hip fracture repair, elective hip and knee procedures showed high variation in particular years. Both the rate and level of variation for knee arthroscopy rates appears to have decreased over time. Variation for lumbar spine interventions, and particularly spinal injections, is very high. From exploratory analysis, total joint replacement rates were found to be associated with population-level variables, with hip replacement rates being higher in rural areas and hip and knee replacement rates associated with higher unemployment. Lumbar spine intervention rates were associated with service-level variables including numbers of referral hospitals and markers of waiting list length. The proportion of patients using private insurance, which could be a proxy for the availability of private hospital care in an area, was associated with higher rates of hip replacement, knee replacement and lumbar spinal procedures.

\section{Findings in relation to other studies}

Our finding that standardised hip replacement rates are higher in rural areas is similar to several studies from the UK, Europe and the USA. ${ }^{7-9}{ }^{32-35}$ Even when not associated with overall population density, rates have been found to be particularly low in large cities. ${ }^{7-9}$ Dixon and colleagues in England hypothesise that in their study, the absence of data from private hospitals could explain this finding, as they are mostly located in urban centres. ${ }^{9}$ This is also possible in our study, however the urban/ 

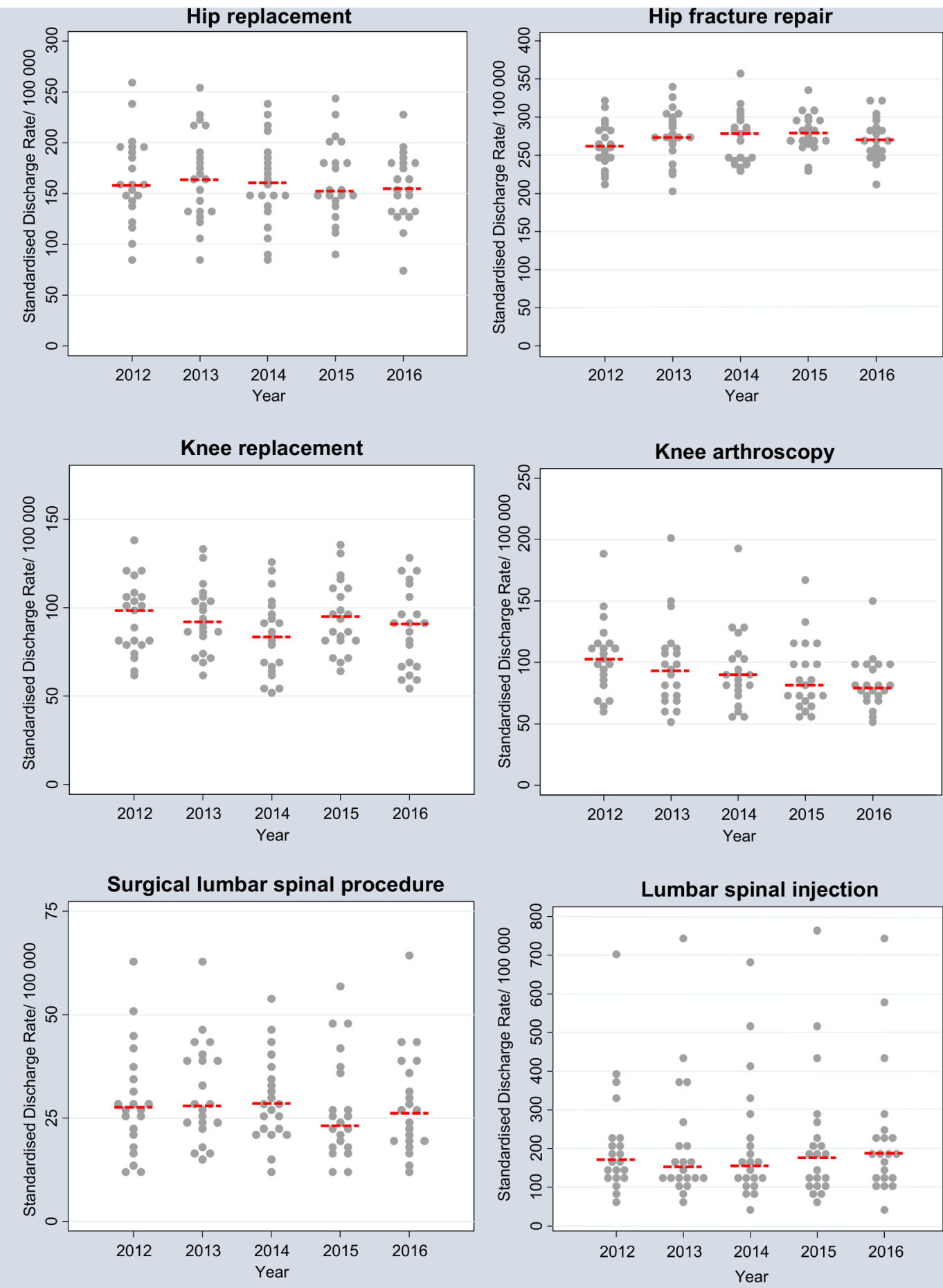

Figure 1 Dotplots of standardised discharge rates per 100000 population for different procedures (2012-2016). Legend: each dot represents a geographical area. The red dashed line shows the median value for each year.

rural relationship remained even when the proportion of patients with private insurance was included in the model. Alternatively, it has been suggested that the infrastructure in large cities could lead to lower perceived disability and may allow patients with hip arthritis to manage for longer without surgery. ${ }^{8}$
As in our study, knee replacement rates in England have been found to be higher in areas of social deprivation. ${ }^{35}$ This could be explained by incidence of disease as opposed to access to services. A Spanish study found that after adjusting for age and gender, residents in areas of highest socioeconomic deprivation had a $50 \%$ increased 
Table 2 Quantifying variation

\begin{tabular}{|c|c|c|c|c|c|c|}
\hline \multirow[b]{2}{*}{ Procedure } & \multirow[b]{2}{*}{ Year } & \multicolumn{2}{|c|}{$\begin{array}{l}\text { Standardised discharge rate by } \\
\text { area }\end{array}$} & \multicolumn{3}{|c|}{ Measures of geographical variation } \\
\hline & & Min & Max & EQ & CV & SCV \\
\hline \multirow[t]{5}{*}{ Hip replacement } & 2012 & 82.1 & 258.4 & 3.1 & 26.1 & $7.7^{\star}$ \\
\hline & 2013 & 85.7 & 255.2 & 3.0 & 26.5 & $7.5^{\star}$ \\
\hline & 2014 & 84.0 & 236.0 & 2.8 & 26.4 & $8.3^{*}$ \\
\hline & 2015 & 89.0 & 245.9 & 2.8 & 24.0 & $6.7^{\star}$ \\
\hline & 2016 & 73.5 & 226.8 & 3.1 & 21.8 & $5.7^{\star}$ \\
\hline \multirow[t]{5}{*}{ Knee replacement } & 2012 & 61.9 & 137.7 & 2.2 & 21.9 & 4.3 \\
\hline & 2013 & 60.5 & 133.1 & 2.2 & 20.4 & 3.1 \\
\hline & 2014 & 51.6 & 124.7 & 2.4 & 25.9 & $5.7^{\star}$ \\
\hline & 2015 & 64.1 & 135.0 & 2.1 & 21.3 & 3.5 \\
\hline & 2016 & 54.0 & 128.0 & 2.4 & 26.1 & 5.5 \\
\hline \multirow[t]{5}{*}{ Knee arthroscopy } & 2012 & 58.0 & 188.0 & 3.2 & 28.9 & $10.0 \dagger$ \\
\hline & 2013 & 52.4 & 202.2 & 3.9 & 36.4 & $13.8 \dagger$ \\
\hline & 2014 & 54.5 & 191.4 & 3.5 & 33.3 & $12.5 \dagger$ \\
\hline & 2015 & 55.3 & 165.9 & 3.0 & 32.1 & $11.0 \dagger$ \\
\hline & 2016 & 53.0 & 149.6 & 2.8 & 25.2 & $6.1^{*}$ \\
\hline \multirow{5}{*}{$\begin{array}{l}\text { Surgical lumbar } \\
\text { spinal procedure }\end{array}$} & 2012 & 11.4 & 62.4 & 5.5 & 45.0 & $15.0 \dagger$ \\
\hline & 2013 & 15.4 & 62.8 & 4.1 & 38.8 & $12.0 \dagger$ \\
\hline & 2014 & 12.4 & 53.5 & 4.3 & 35.0 & $9.2^{*}$ \\
\hline & 2015 & 12.1 & 56.4 & 4.6 & 46.1 & $16.9+$ \\
\hline & 2016 & 11.5 & 63.8 & 5.6 & 44.1 & $14.2 \dagger$ \\
\hline \multirow{5}{*}{$\begin{array}{l}\text { Lumbar } \\
\text { spinal injection }\end{array}$} & 2012 & 60.0 & 705.9 & 11.8 & 67.4 & $41.3+$ \\
\hline & 2013 & 57.1 & 739.3 & 12.9 & 76.4 & $54.5+$ \\
\hline & 2014 & 48.9 & 680.0 & 13.9 & 75.7 & $56.2 \dagger$ \\
\hline & 2015 & 57.3 & 770.7 & 13.4 & 78.6 & $60.9+$ \\
\hline & 2016 & 49.3 & 737.7 & 14.0 & 72.9 & $52.6+$ \\
\hline \multirow{5}{*}{$\begin{array}{l}\text { Hip fracture } \\
\text { repair }(50+\text { years })\end{array}$} & 2012 & 211.5 & 322.0 & 1.5 & 11.3 & 0.4 \\
\hline & 2013 & 202.8 & 341.5 & 1.7 & 12.4 & 1.0 \\
\hline & 2014 & 230.5 & 357.2 & 1.5 & 12.4 & 0.7 \\
\hline & 2015 & 230.4 & 333.1 & 1.4 & 10.5 & 0.0 \\
\hline & 2016 & 213.3 & 323.8 & 1.5 & 8.6 & 0.2 \\
\hline
\end{tabular}

*High variation.

†Very high variation (SCV >3 likely be to 'medical discretion'; 5-10=high variation; $>10$ very high variation).

SCV, systematic component of variance.

risk of clinical knee osteoarthritis but only $25 \%$ higher risk of hip disease. ${ }^{36}$ This difference in osteoarthritis prevalence could be related to higher rates of manual occupations and potentially higher rates of overweight and obesity in socially deprived areas. ${ }^{36}{ }^{37}$ This could have orthopaedic and broader healthcare service implications as obesity is associated with increased surgical risk and can dissuade surgeons from operating. ${ }^{58}$ In our study, knee replacement rate was particularly low in 2014 which could in part be explained by the economic recession. Construction workers, who were disproportionately affected by job insecurity and emigration may have deferred seeking elective procedures. ${ }^{39}$ Knee arthroscopy rate was also associated with higher unemployment in univariable analysis but as both decreased over time, the relationship did not remain significant in multivariable analysis.

The observed decrease in knee arthroscopy rate is in line with international trends and strengthening evidence that medical management results in similar benefits for osteoarthritis and meniscal tears. ${ }^{40-42}$ The high variation observed for this procedure may suggest that some areas were slower than others in adopting updated evidence. Patients receiving arthroscopy were younger than those 
Table 3 Variables for explaining variation at area level

\begin{tabular}{|c|c|c|}
\hline & Mean (SD) & Range \\
\hline $\begin{array}{l}\text { Proportion of population in } \\
\text { urban areas (2012-2016) }\end{array}$ & $51.1 \%(19.8 \%)$ & $27.3 \%-98.9 \%$ \\
\hline Unemployment rate (2012) & $18.9 \%(2.4 \%)$ & $15.2 \%-24.5 \%$ \\
\hline Unemployment rate (2016) & $13.9 \%(2.1 \%)$ & $10.6 \%-18.0 \%$ \\
\hline \multicolumn{3}{|l|}{ Hip replacement } \\
\hline$\%$ Private patients & $26.1 \%(10.9 \%)$ & $8.9 \%-63.8 \%$ \\
\hline No. of referral hospitals & $1.8(0.5)$ & $1-3$ \\
\hline$\%>6$ months on waitlist & $21.7 \%(13.0 \%)$ & $0 \%-48.5 \%$ \\
\hline \multicolumn{3}{|c|}{ Knee replacement } \\
\hline$\%$ Private patients & $25.3 \%(12.8 \%)$ & $7.5 \%-68.4 \%$ \\
\hline No. of referral hospitals & $1.8(0.5)$ & $1-3$ \\
\hline$\%>6$ months on waitlist & $21.7 \%(13.0 \%)$ & $0 \%-48.5 \%$ \\
\hline \multicolumn{3}{|l|}{ Knee arthroscopy } \\
\hline$\%$ Private patients & $33.9 \%(15.8 \%)$ & $9.7 \%-75.2 \%$ \\
\hline No. of referral hospitals & $2.0(1.1)$ & $1-5$ \\
\hline$\%>6$ months on waitlist & $20.6 \%(13.8 \%)$ & $0 \%-48.1 \%$ \\
\hline \multicolumn{3}{|c|}{ Surgical lumbar spinal procedure } \\
\hline$\%$ Private patients & $30.5 \%(19.2 \%)$ & $0 \%-72.4 \%$ \\
\hline No. of referral hospitals & $2.5(1.1)$ & $1-5$ \\
\hline$\%>6$ months on waitlist & $33.0 \%(12.0 \%)$ & $0 \%-57.7 \%$ \\
\hline \multicolumn{3}{|l|}{ Lumbar spinal injection } \\
\hline$\%$ Private patients & $28.2 \%(9.2 \%)$ & $12.5 \%-55.1 \%$ \\
\hline No. of referral hospitals & $2.9(1.3)$ & $1-6$ \\
\hline$\%>6$ months on waitlist & $25.1 \%(11.9 \%)$ & $4.3 \%-46.7 \%$ \\
\hline \multicolumn{3}{|l|}{ Hip fracture repair } \\
\hline$\%$ Private patients & $24.2 \%(7.5 \%)$ & $6.3 \%-42.5 \%$ \\
\hline No. of hospitals & $1.4(0.7)$ & $1-3$ \\
\hline
\end{tabular}

with joint replacements (mean age 46 versus mean age 66). Previous studies have described arthroscopies being used for traumatic injuries mostly in younger males and osteoarthritis in older adults. ${ }^{43}$ These groups could be explored separately in future work. The observed day case rate for arthroscopies was $78 \%$ which is much lower than the current goal in Ireland of $95 \% .^{5}$ This could be an area for potential service improvement. When one area with particularly high rates of arthroscopies is excluded, observed variation is lower (see online supplementary table 3). Although the maximum rate is decreasing with the national trend, it remains notably higher than the median (see figure 1). It would require further investigation to determine whether this variation is unwarranted or related to higher burden of disease.

The higher variation observed for spinal procedures is in line with international research, due to the effectiveness of these procedures being more uncertain in comparison to joint replacements. ${ }^{11}$ Current guidelines recommend that spinal procedures and injections should only be considered for a number of defined indications after completing conservative management options including physiotherapy, with the exception of a few conditions that require urgent review. ${ }^{13}$ Despite this, there has been an $80 \%$ increase in the number of spinal injections administered between 2005 and 2012 in Ireland, consistent with international trends. ${ }^{44}$ In contrast to joint replacements, we found these procedures to be associated with service-level rather than demographic-level variables. The association of spinal procedure rates with a lower number of referral centres could potentially be explained by the development of specialised centres with subsequent increased referral of local residents. ${ }^{9}$ The magnitude of geographic variation observed for spinal injections, specifically with regard to five areas in Ireland, may suggest that decision making is concentrated among the few (eg, surgeons) rather than patients. ${ }^{11}$ In Canada, enthusiasm for surgery among surgeons but not among patients or general practitioners (GPs) was found to be associated with increased rates of lumbar spinal surgery. ${ }^{45}$ This may also be the case with injections. Alternatively, this could be a marker of supply-sensitive care as several specialties now carry out this procedure, including orthopaedic surgeons, neurosurgeons, radiologists and pain specialists. Further research, including surveys with providers, may help to reveal explanations for very high rates of injections in particular areas in Ireland.

\section{Strengths and weaknesses of the study}

This study provides a national picture of procedures conducted through publicly funded hospitals in Ireland using a very large dataset which is known to have good coverage and accuracy. ${ }^{20}$ As recent healthcare policy and reforms in the country have placed an increased focus on prioritising equitable access to care according to need rather than ability to pay, we believe that it is important to explore variation across public hospitals. ${ }^{16}$ The absence of data from the private sector is a limitation of our analysis and it does not therefore reflect all surgical activity in the country. In 2015, it was estimated that private hospitals accounted for $31 \%$ of day patient admissions and $15 \%$ of inpatient bed days in Ireland. ${ }^{46}$ The Private Hospitals Association have also reported that approximately $50 \%$ of all elective procedures in 2015 were performed in private hospitals. ${ }^{19}$ Further details of private hospital activity or specific procedures performed however cannot be determined from available information. This has been a consistent limitation encountered by policy-informing research in Ireland to date. ${ }^{46}$ This difficulty has also been cited as a limitation in previous research in orthopaedic geographical variation in England. ${ }^{9}$ The absence of private hospital data may in part explain the observed low rates of particular procedures in urban areas or in areas of lower social deprivation, as private hospitals are mostly located in cities and are accessible by those who can afford private health insurance. ${ }^{916}$ We did however attempt to account for this potential source of variation by including the proportion of patients covered by private health insurance for each procedure in the analysis as low numbers of private patients in public hospitals could signal that 
private hospitals are treating eligible patients in the area. This hypothesis is supported by the observed association between private cover and higher rates of several procedures in this study. An Irish National Orthopaedic Registry for joint replacements is currently being established and it is hoped that this will include private sector data as has been the case in other countries. ${ }^{847}$ This could provide further insights in future research. To our knowledge however, there are no plans for a registry for spinal procedures or injections for which there is highest level of geographic variation.

The primary aim of this study was to estimate the extent of geographical variation in the procedures under study. Our analysis of potential factors associated with standardised discharge rates should be considered exploratory as it was limited by lack of information available at the geographical level of interest. This challenge has been encountered by similar studies in Spain and England. ${ }^{9}{ }^{36}$ We derived a variable in relation to the length of waiting lists to represent healthcare supply factors. ${ }^{24}$ We are unable to determine however if wait times for specific procedures and those with specific areas of residence are accurately represented by this variable. Furthermore there are several potentially important factors that we were unable to explore including the availability of conservative options (ie, physiotherapy).$^{45}$

Geographical areas were chosen for this study based on county boundaries in Ireland. While this decision was primarily due to data availability we also believe these units of analysis to be meaningful for clinical decision makers. Healthcare boundaries are complex in Ireland as geographical regions for primary and secondary care are not coterminous. Furthermore, governance boundaries of the secondary care system changed during period of this study. In 2013, acute hospitals were divided into seven 'Hospital Groups' for decision-making purposes. ${ }^{48}$ It is therefore likely that there is interdependence across our areas that has changed over time. ${ }^{1249}$ This is in contrast to the methods of the Dartmouth Atlas of Healthcare Variation in the USA where relatively independent areas could be constructed based on specific healthcare markets. ${ }^{12} 23$

Definitions and denominators chosen in this study are in line with previous Irish analyses. ${ }^{5}{ }^{13}$ We included all age groups except for with hip fractures where we excluded those under 50 years. Many similar studies in the USA include only those over the age of 65 , while in the Australian Atlas of Variation the study of knee arthroscopies has been limited to those over the age of $55 .{ }^{11} 2350$ Additionally, national atlases of healthcare variation in different countries have included different specific procedures. For example, in Australia revision procedures have been included in studies of joint replacements, while in England and the USA they have not been. ${ }^{22}{ }^{2350}$ For these reasons, although we can assess general trends, it would not be appropriate to directly compare standardised rates for procedures found in this study with international work. Future research is planned to explore differences in variation measures and standardised rates when definitions aligned to the atlases of healthcare variation in different countries are applied to Irish data.

\section{Clinical implications}

Much of the research aiming to decrease the geographical variation of preference-sensitive care has focused on improving shared decision making. ${ }^{115152}$ Supply-sensitive variation is more difficult to address. ${ }^{11}$ Published recommendations for the reduction of variation in musculoskeletal procedures in Ireland include introducing referral thresholds based on imaging findings and the success of conservative treatment. ${ }^{513} \mathrm{GPs}$ in Ireland however report limited direct access to publicly funded MRI and physiotherapy services. ${ }^{5} 135354$ Since 2011 in Ireland, Advanced Practice Musculoskeletal Physiotherapist posts have been established in many hospitals to enable multidisciplinary triage of GP referrals. In 1 year, almost 14000 new patients were seen, most commonly for knee (23\%) and lower back (22\%) pain with only $20 \%$ being subsequently referred to consultant physicians. ${ }^{55}$ These clinics have the potential to speed up access to specialised assessments, aid patient education and shared-decision making and facilitate appropriate conservative management ${ }^{55} 56$ but whether this can reduce the geographic variation observed in our study requires further research.

\section{CONCLUSION}

This study provides a national picture of variation across musculoskeletal procedures conducted through public hospitals in Ireland. The level of variation and factors associated with standardised rates for hip and knee procedures is in line with research conducted internationally. In keeping with growing evidence in favour of medical management, knee arthroscopy rates in Ireland are falling. Of concern, we found very high levels of variation across procedures used to treat lumbar degenerative disease. Further research is needed to explore the reasons for very high rates of spinal injections in particular areas in Ireland. Future work should also evaluate service changes that have the potential to reduce variation in musculoskeletal procedure rates including the development of multidisciplinary triage clinics.

Acknowledgements The authors would like to acknowledge the assistance of Dr Howard Johnson and the team from Health Intelligence Ireland, HSE for facilitating access to national HIPE data and of the National Treatment Purchase Fund for providing waiting list data.

Contributors MEW and TF conceptualised the study. FB and MEW analysed the data and MEW, FB, TF and JMOB interpreted the results. MEW wrote the original draft and TF, FB and JMOB contributed to the editing and reviewing of the paper.

Funding Support was received from the Health Research Board (HRB) in Ireland through grant no. HRC/2014/1 (TF).

Competing interests None declared.

Patient consent for publication Not required.

Provenance and peer review Not commissioned; externally peer reviewed.

Data sharing statement Access to Hospital Inpatient Enquiry system data was requested and accessed through Health Intelligence Ireland, HSE. Data on Inpatient Waiting Lists is publically available from National Treatment Purchase Fund from 
2014 at www.ntpf.ie. Census data is publically available from the Central Statistics Office at http://www.cso.ie/en/census/interactivetables/.

Open access This is an open access article distributed in accordance with the Creative Commons Attribution Non Commercial (CC BY-NC 4.0) license, which permits others to distribute, remix, adapt, build upon this work non-commercially, and license their derivative works on different terms, provided the original work is properly cited, appropriate credit is given, any changes made indicated, and the use is non-commercial. See: http://creativecommons.org/licenses/by-nc/4.0/.

\section{REFERENCES}

1. Birkmeyer JD, Reames BN, McCulloch P, et al. Understanding of regional variation in the use of surgery. Lancet 2013;382:1121-9.

2. Wennberg JE. Time to tackle unwarranted variations in practice. BMJ 2011;342:d1513.

3. Corallo AN, Croxford R, Goodman DC, et al. A systematic review of medical practice variation in OECD countries. Health Policy 2014:114:5-14.

4. National Institute for Health and Care Excellence. Osteoarthritis: care and management. NICE guideline 2014.

5. Health Information and Quality Authority. Health Technology Assessment of Scheduled Procedures Phase III. Dublin, 2014. https://www.hiqa.ie/reports-and-publications/health-technologyassessments/hta-scheduled-procedures-phase-ii. (Accessed 20 Jun 2018).

6. Weeks WB, Jardin M, Dufour JC, et al. Geographic variation in admissions for knee replacement, hip replacement, and hip fracture in France: evidence of supplier-induced demand in for-profit and notfor-profit hospitals. Med Care 2014;52:909-17.

7. Pedersen $A B$, Johnsen SP, Overgaard S, et al. Regional variation in incidence of primary total hip arthroplasties and revisions in Denmark, 1996-2002. Acta Orthop 2005;76:815-22.

8. Mäkelä KT, Peltola M, Häkkinen U, et al. Geographical variation in incidence of primary total hip arthroplasty: a population-based analysis of 34,642 replacements. Arch Orthop Trauma Surg 2010;130:633-9.

9. Dixon T, Shaw ME, Dieppe PA. Analysis of regional variation in hip and knee joint replacement rates in England using Hospital Episodes Statistics. Public Health 2006;120:83-90.

10. Weinstein JN, Bronner KK, Morgan TS, et al. Trends and geographic variations in major surgery for degenerative diseases of the hip, knee, and spine. Health Aff 2004;Suppl Variation:VAR-81--80.

11. Lurie JD, Bell JE, Weinstein J. What rate of utilization is appropriate in musculoskeletal care? Clin Orthop Relat Res 2009;467:2506-11.

12. Bernal-Delgado E, García-Armesto S, Peiró S. Atlas VPM Group. Atlas of Variations in Medical Practice in Spain: the Spanish National Health Service under scrutiny. Health Policy 2014;114:15-30.

13. Health Information and Quality Authority. Health technology assessment of scheduled procedures phase II. 2013 https://www. hiqa.ie/reports-and-publications/health-technology-assessments/ hta-scheduled-procedures-phase-ii (Accessed 20 Jun 2018).

14. Westert GP, Groenewoud S, Wennberg JE, et al. Medical practice variation: public reporting a first necessary step to spark change. Int J Qual Health Care 2018;30:731-5.

15. von Elm E, Altman DG, Egger M, et al. The Strengthening the Reporting of Observational Studies in Epidemiology (STROBE) Statement: guidelines for reporting observational studies. Int J Surg 2014:12:1495-9.

16. Wren MA, Connolly S. A European late starter: lessons from the history of reform in Irish health care. Health Econ Policy Law 2017;26:1-19.

17. National Treatment Purchase Fund. National Waiting List Data. 2018 http://www.ntpf.ie/home/nwld.htm (Accessed 14 Mar 2018).

18. Brown KM. Health insurance authority - a review of private health insurance in Ireland. 2017 https://www.hia.ie/publication/consumersurveys (Accessed 12 Jan 2019).

19. Private Hospitals Association. Submissission to the oireachtas committee on healthcare. 20162016. Dublin http://privatehospitals.ie/ pha-submission-oireachtas-committee-future-healthcare/ (Accessed 25 Jan 2019)

20. Healthcare Pricing Office. Hospital in-patient enquiry (hipe) data dictionary 2015, version 7.0. Available at www.hpo.ie/hipe/hipe data_dictionary/HIPE_Data_Dictionary_2015_V7.0.pdf (Accessed 12 Jan 2019).

21. National Centre for Classification in Health. The International Statistical Classification of Diseases and Related Health Problems, Tenth Revision, Australian Modification (ICD-10-AM). Sydney: The University of Sydney, 1998.
22. NHS Atlas of Variation in Healthcare 2015. Public Health England. 2015 http://tools.england.nhs.uk/images/atlas15/atlas.html (Accessed 20 Jun 2018)

23. Weinstein J, Dartmouth Medical School,. The Dartmouth Atlas of Musculoskeletal Health Care. Chicago, IL: AHA Press, 2000.

24. Widmer M, Matter P, Staub L, et al. Regional variation in orthopedic surgery in Switzerland. Health Place 2009;15:791-8.

25. Central Statistics Office. CSO Statistical Databases 2017. Dublin. 2017. Available at https://www.cso.ie/en/databases/ (Accessed 12 Jan 2019).

26. Thygesen LC, Baixauli-Pérez C, Librero-López J, et al. Comparing variation across European countries: building geographical areas to provide sounder estimates. Eur J Public Health 2015;25 Suppl 1(Suppl 1):8-14.

27. European Commision. Revision of the European Standard Population- Report of Eurostat's task force. Luxembourg: Publications Office of the European Union, 2013. https://ec.europa. eu/eurostat/documents/3859598/5926869/KS-RA-13-028-EN.PDF/ e713fa79-1add-44e8-b23d-5e8fa09b3f8f. (Accessed 20 Jun 2018).

28. Ibáñez B, Librero J, Bernal-Delgado $\mathrm{E}$, et al. Is there much variation in variation? Revisiting statistics of small area variation in health services research. BMC Health Serv Res 2009;9:60.

29. McPherson $\mathrm{K}$, Wennberg JE, Hovind OB, et al. Small-area variations in the use of common surgical procedures: an international comparison of New England, England, and Norway. N Engl J Med 1982;307:1310-4.

30. Filc D, Davidovich N, Novack L, et al. Is socioeconomic status associated with utilization of health care services in a single-payer universal health care system? Int J Equity Health 2014;13:115.

31. Eaton LH, Langford DJ, Meins AR, et al. Use of self-management interventions for chronic pain management: A comparison between rural and nonrural residents. Pain Manag Nurs 2018;19:8-13.

32. Francis ML, Scaife SL, Zahnd WE, et al. Joint replacement surgeries among medicare beneficiaries in rural compared with urban areas. Arthritis Rheum 2009;60:3554-62.

33. Willis CE, Kee F, Beverland D, et al. Urban-rural differences in total hip replacements: the next stage. J Public Health Med 2000;22:435-8.

34. Dunsmuir RA, Allan DB, Davidson LA. Increased incidence of primary total hip replacement in rural communities. BMJ 1996;313:1370.

35. Judge A, Welton NJ, Sandhu J, et al. Equity in access to total joint replacement of the hip and knee in England: cross sectional study. BMJ 2010;341:c4092.

36. Reyes C, Garcia-Gil M, Elorza JM, et al. Socio-economic status and the risk of developing hand, hip or knee osteoarthritis: a region-wide ecological study. Osteoarthritis Cartilage 2015;23:1323-9.

37. Kearns K, Dee A, Fitzgerald AP, et al. Chronic disease burden associated with overweight and obesity in Ireland: the effects of a small BMI reduction at population level. BMC Public Health 2014;14:143

38. Odum SM, Springer BD, Dennos AC, et al. National obesity trends in total knee arthroplasty. J Arthroplasty 2013;28:148-51.

39. Bergin A, Kelly E. The labor market in Ireland, 2000-2016. IZA World of Labor 2018:410.

40. Howard DH. Trends in the Use of Knee Arthroscopy in Adults. JAMA Intern Med 2018;178:1557.

41. Kirkley A, Birmingham TB, Litchfield RB, et al. A randomized trial of arthroscopic surgery for osteoarthritis of the knee. N Engl J Med 2008;359:1097-107.

42. Mattila VM, Sihvonen R, Paloneva J, et al. Changes in rates of arthroscopy due to degenerative knee disease and traumatic meniscal tears in Finland and Sweden. Acta Orthop 2016;87:5-11.

43. Hawker G, Guan J, Judge A, et al. Knee arthroscopy in England and Ontario: patterns of use, changes over time, and relationship to total knee replacement. J Bone Joint Surg Am 2008;90:2337-45.

44. Manchikanti L, Pampati V, Hirsch JA. Retrospective cohort study of usage patterns of epidural injections for spinal pain in the US fee-for-service Medicare population from 2000 to 2014. BMJ Open 2016;6:e013042.

45. Bederman SS, Coyte PC, Kreder HJ, et al. Who's in the driver's seat? The influence of patient and physician enthusiasm on regional variation in degenerative lumbar spinal surgery: a population-based study. Spine 2011;36:481-9.

46. Keegan C, Brick A, Wren M. An examination of activity in public and private hospitals in Ireland, 2015. Working Paper No. 601. Dublin: Economic and Social Research Institute, 2018. https://www.esri. ie/publications/an-examination-of-activity-in-public-and-privatehospitals-in-ireland-2015. (Accessed 12 Jan 2019).

47. Cahill N. Plan to detect joint hip replacements may not include all private hospitals. The Irish Times. 2018 https://www.irishtimes. com/news/crime-and-law/plan-to-detect-joint-hip-replacementsmay-not-include-all-private-hospitals-1.3550214 (Accessed 20 Jun 2018). 
48. Department of Health. Health service capacity review 2018 review of health demand and capacity requirements in Ireland to 2031- Main report. London, United Kingdom: PA Knowledge Limited, 2018. https://health.gov.ie/blog/publications/health-service-capacityreview-2018/. (Accessed 12 Jan 2018).

49. Thomas S, Burke S, Barry S. The Irish health-care system and austerity: sharing the pain. Lancet 2014;383:1545-6.

50. Australian Commision on Safety and Quality in Health Care. The second australian atlas of healthcare variation. $2017 \mathrm{https} / / / \mathrm{www}$. safetyandquality.gov.au/atlas/ (Accessed 14 Mar 2018).

51. Veroff D, Marr A, Wennberg DE. Enhanced support for shared decision making reduced costs of care for patients with preferencesensitive conditions. Health Aff 2013;32:285-93.

52. Stacey D, Taljaard M, Dervin G, et al. Impact of patient decision aids on appropriate and timely access to hip or knee arthroplasty for osteoarthritis: a randomized controlled trial. Osteoarthritis Cartilage 2016;24:99-107.

53. O'Riordan M, Doran G, Collins C. Access to diagnostics in primary care and the impact on a primary care led health service. Ir Med $J$ 2015;108:53-5.

54. Ní Shúilleabháin A, O'Kelly M, O'Kelly F, et al. Limited options: a report on GP access to services. Ir J Med Sci 2007;176:27-32.

55. Fennelly $\mathrm{O}$, Blake $\mathrm{C}$, FitzGerald $\mathrm{O}$, et al. Advanced practice physiotherapy-led triage in Irish orthopaedic and rheumatology services: national data audit. BMC Musculoskelet Disord 2018;19:181.

56. NHS England. Transforming musculoskeletal and orthopaedic elective care service- A handbook for local health and care systems. 2017. https://www.england.nhs.uk/wp-content/uploads/2017/11/ msk-orthopaedic-elective-care-handbook-v2.pdf (Accessed 14 Mar 2018). 